Rasim M. Alguliyev' ${ }^{1}$, Masuma H. Mammadova ${ }^{2}$

${ }^{1,2}$ Institute of Information Technology of ANAS, Baku, Azerbaijan

${ }^{1}$ rasim@science.az, ${ }^{2}$ masuma.huseyn@iit.ab.az

\title{
ESSENCE, OPPORTUNITIES AND SCIENTIFIC PROBLEMS OF E-MEDICINE
}

The article examines the factors and trends defining the necessity of the formation of electronic medicine. It also highlights the purpose, essence and capabilities of e-medicine. Moreover, the international experience in the field of e-medicine and the situation with its formation in Azerbaijan are reviewed. The weaknesses of the scientific basis for informatization of health are mentioned, and the improvement of e-medicine through the solution of problems requiring scientific support are identified. Suggestions on the development of e-medicine in Azerbaijan are put forward.

Keywords: e-health, e-medicine, person-oriented approach, electronic health records, scientific problems of e-medicine.

\section{Introduction}

At present, the daily activity in the field of healthcare and medicine in any country is based on information and communication and depend on their core technologies. The necessity of the integration of information and communication technologies (ICTs) into health is increasing. It also deals with the provision of high-quality and safe medical services for citizens, reporting and accounting and medical surveys covering the efficient deployment of personnel, statistical data collection, protection, processing and transmission procedures. All of these, in turn, raise the need for comprehensive informatization of health care.

This article aims at the investigation of the factors and tendencies that shape the formation of e-medicine, the analysis of the essence and benefits of electronic health (e-health), the analysis of the informatization of the tendencies and the identification of the major problems in the development process of the national e-health system.

\section{Factors and trends imposing e-medicine formation}

The World Health Organization (WHO) defines e-health as the use of ICT in medicine and health [1].

In a broad sense, e-health serves to improve the information flow by using electronic tools to deliver healthcare services and support health management systems [2]. The application of ICT offers a new set of services that will eliminate the dependence on the user's location [3].

The arguments supporting the application of ICT in the health and medical sector are already in sight for many decades. The experience of many countries shows that the advancement of ehealth to the strategic planning in the field of health has been achieved due to the crisis in this sector, which are provided by numerous factors [4]. These factors include:

- minor changes in the data collection, storage and processing generated in the process of treatment of patients in the background of the wide use of high-tech equipment for the diagnosis and treatment of diseases;

- demographic processes: a) low birth rates, aging and an increase in elderly population in the developed countries; b) rapid growth in the young population in the developing countries;

- numerous cases where the content of the medical documents is unrecoverable or difficult to be recovered;

- opening several medical records of a patient in various polyclinics and diagnostic centers he/she applies due to the lack of information communications between the treatment facilities and the failure to ensure the confidentiality of the medical data stored on paper;

- wasting $40 \%$ of the time by doctors and medical personnel for the documentation and 
search of the necessary information;errors occurring due to incompleteness or inaccessibility of medical information affecting the quality of the provided services [5];

- need for physicians' decisions in the context of perception, coordination and analysis of large amounts of information [6];

- statistics of physician errors, which clearly demonstrate the gradual "deepening cracks" of the traditional model of the healthcare system [7].

At the same time, ICT has created a new public trend for the health workers and healthcare system, as a whole. The catalyst of this tendency is the Internet, which provides access to information and leads to the exceptional scale of communication between millions of people around the world $[8,9]$.

As a key source of information and a basic infrastructure for the fast, secure and reliable data transfer processes, the Internet has led to the emergence of new realities in medicine:

- medical knowledge has become accessible to everybody by attaining a new status, and the availability of numerous medical information on the Internet;

- relationships inherent to the real medical system are simulated in virtual space. Establishing contacts with the patients through the Internet in the virtual information space enables establishing the virtual medical societies providing remote medical consultation, i.e., the interaction of the actors participating in the health system in the new reality is forming;

- tendency of transiting to the treatment at home has developed and is expanding, which involves the monitoring of the condition of the patient through the Internet;

- preference of ambulatory and preventive treatment compared to stationary treatment is one of the trends observed in modern healthcare;

- involvement of a citizen in the protection of own health and provision of the control of the patients at home, consultation of physicians and counseling have become one of the fundamental components of the reforms in health systems of the developed countries;

- provision of the doctors-specialists' services to the remote populations through the Internet will considerably reduce financial costs.

All these factors and trends, including the increasing need for public health services, have led to the integration of modern ICT into healthcare in the developing countries. ICT can be a driving force in addressing many serious problems and improving the health care performance without investing large amounts of money in this field. In this regard, one of the main implementation fields of ICT specified in the Action Plan of the World Summits on Information Society held in Geneva in 2003 and in Tunisia in 2005 is medicine [10].

\section{Establishment of e-medicine}

The development of the health services market and the introduction of ICT in this field have been included to the priorities since 2000. G8 project on Global Health Governance (G8) in 2000 is the starting point for eHealth. As a next step, the resolution discussed in the 58th session of the World Health Assembly in 2005 and adopted by WHO, including the E-health concept should be mentioned. This resolution emphasizes an important role of e-health in increasing the quality of health care and improving the quality of health and health-related activities.

The challenges addressed to the states by the WHO on e-health include:

- development of strategic plans and legal basis for the implementation of e-health services;

- mobilization of participants and co-ordination of stakeholders;

- establishment of national centers for comparative analysis of activities and identification of best practice [11].

E-health and telemedicine has been included into the European Union (EU) agenda with the Lisbon Strategy at late 1990s. This political document has emphasized a vital role ICT of in the 
modernization of health. This strategy was later titled "E-health". In 2008, European Commission declared e-health as one of the six key EU initiatives [12].

The Organization for Economic Cooperation and Development (OECD) considers the application of ICT in medicine as a key driving force for economic growth, particularly in the developing countries [13]. The OECD believes that when telemedicine and telehealth are a part of the complex utilization of telecommunications and information technologies, their economic efficiency is significantly improved [14].

WHO Global Observatory for E-Health has been set up to combine efforts by the world's medical community to informatize the healthcare [15].

\section{Terminological problems of e-medicine}

The study of the terminological problems of e-medicine revealed that the term "telemedicine" started to be widely used and accepted in the mid-1990s. Later, the authors began to distinguish the terms "telemedicine", "e-medicine", "e-health", and "telehealth". At present, there is no definite approach to the scope of these terms offered by the researchers. However, the following views are available [15-19]:

1. E-health, including e-medicine (telemedicine) are broader terms. In this sense, the term e-health covers a variety of information and communication and medical services delivered remotely (mostly over the Internet).

2. E-medicine, telemedicine and e-health are different concepts. Thus, e-medicine covers medical services such as tele-recordiology, tele-radiology, tele-pathology, teleophthalmology, tele-dermatology, and tele-surgery. E-health also includes the use of ICT, medical communication services, picture archiving and communication systems (PACS), medical information systems (MIS), e-education, and electronic prescription of medicaments in health care.

3. Telemedicine (e-medicine) and telehealth (e-health) are the same concepts.

The American telemedicine agency has historically believed that telemedicine (e-medicine) and telehealth (e-health) are synonymous terms that cover a wide range of health care services. Providing the consultations to the patients via videoconference and various portals; remote diagnosis of essential functions; transmission and exchange of medical images, laboratory analysis, electronic data, reporting and accounting and management data, including continuous medical education; establishment and expansion of wireless communication taking into account the wishes and suggestions of the patient; and information support for medical research, are considered as parts of e-medicine and e-health.

Evidently, the terms e-medicine and e-health were first used by ICT managers and marketers as the notions e-commerce, e-business, and e-solutions. At the same time, this term can be regarded as an attempt to advertise the new opportunities of the Internet in healthcare for the users.

Due to the lack of unambiguous approaches to "e-medicine", "telemedicine" and "e-health", today there are no single definitions. Thus, there are many definitions of these terms in literature.

In the academic environment, some researchers believe that the term e-health should remain in the business and marketing environment and should be avoided in scientific and medical literature. However, given the fact that this term has already included into scientific literature, a group of researchers has given the following definition in line with its scientific tradition:

e-Health is an emerging field in the intersection of medical informatics, public health and business, referring to health services and information delivered or enhanced through the Internet and related technologies. In a broader sense, the term characterizes not only a technical development, but also a state-of-mind, a way of thinking, an attitude, and a commitment for networked, global thinking, to improve health care locally, regionally, and worldwide by using information and communication technology. [20].

In the presented article, the terms "e-medicine" and "e-health" are used as synonyms. 


\section{The goal of e-medicine}

E-medicine is based on the methodology proposed by $\mathrm{WHO}$ and the International Telecommunication Union (ITU) [11-13].

The objectives of e-medicine include:

- improving the quality and accessibility of medical services delivered to the population;

- reducing health resources and expenditures through improved governance;

- constantly informing the population about healthy lifestyles, prevention of diseases, provision of medical services for different purposes and creating the opportunity for each citizen to control their health;

- eliminating the different types of discrimination (age, disability, poverty, etc.) in healthcare provision.

a)Person-oriented approach.

The main priority of the concept of e-medicine is an individual-oriented approach. The main objective of individual-oriented approach is to direct all electronic services and databases to the patient. In other words, all the medical information of a certain individual is "connected" to his/her personal identity, and thereby it is possible to access all this medical information is available at any institution he/she applies to. It dramatically changes the process of interaction between the patient and the medical institution, making it faster, more accurate and effective. All therapeutic and diagnostic processes of the medical institution should be informatized for the realization of the individual-oriented approach.

In this context, e-health is a fusion of the distributed medical databases that provide a distinctive interactive consultation in the system of the relationships between "physician-topatient", "doctor- to- doctor", "doctor-to-nurse", and "medical institution -to - medical institution" basedn on individual-oriented approach. (person-oriented approach)

\section{b) Electronic Health Records (EHR)}

EHR is an electronic analogue of a typical medical record (paper health history) of the patient and stores data from various sources: medical centers, hospitals, doctors, and laboratories. Currently, the following terms are used: electronic medical passport, electronic health records (EHR) or passport, electronic illness history, Electronic Medical Records (EMR).

EHR is a collection of individual medical information (IMI) presented as electronic medical records about the health of the person (individual). EHR consists of general, clinical, biometric, social, economic, financial, insurance and other structured detailed information about the patient. It also ensures documentation of the medical services provided to the patients. EHR implies a medical document drawn up in a computer-comprehensible format and providing access to the adequate and accurate information for decision making and recommendations [22].

EHR aims at providing conditions for the continuity, consistency and quality of treatment, timely implementation of preventive and other measures to protect the health of a particular individual by documenting and maintaining appropriate medical information and its timely delivery to a competent medical personnel $[22,23]$.

It should be noted that the EHR of the patient is filled from birth, and this process continues throughout his/her lifetime. The application of EHR is required to ensure the accessibility of the noncontradictory and complete, operative data anywhere. At the same time, these data must be structured in accordance with the methodology for compiling medical documentation, capable to be interpreted in different languages, and support the decision-making in the appropriate place and time.

Using the EHR, physician gets access to the information needed for decision-making on the treatment of the patient. Moreover, physician spends less time filling in the patient's record and focuses on the immediate communication with the patient. As a result, the quality of medical services provided to the population is increasing. 


\section{The essence and capabilities of e-medicine}

The essence of e-medicine is the presentation of a set of tools that provide secure electronic information on the health of patients at the right place and time [24].

The working principles of collection, processing, usage, transfer and storage of electronic medical information are based on the generation of unified information resources that enable working with personal data of the patients and share this information with other medical institutions. Transition to e-health implies the establishment of networks for the transmission of medical information both locally and globally and the formation of a single information space based on those networks. E-medical infrastructure involves the tools that support both physician decisions and management decisions [25].

A global approach to support of treatment-diagnostics, medical-prophylactic and rehabilitation decisions made by physicians shows that the patient's electronic health records (medical records) constitute the "core" of e-medicine. Since the 80s of the last century, electronic health records (EHR), which enables the digitization of all health data of the patients, have been recognized as successful innovative technologies [22, 23].

At the same time, traditionally, one of the main tasks of the general practitioner is to compile the accounting records timely and properly. EHR also facilitates the work of professionals in this field [26]. EHR integrated on several healthcare facilities are a key element of e-health in many countries around the world.

The introduction of ICT into the healthcare system and the establishment of a single medical information space allows tracking the patient's health status and providing access to them, improving the quality of medical care, and developing the administrative management. The introduction of e-health offers the following opportunities [27, 28]:

- remote monitoring of patients and better dissemination of information among the patients;

- provision of access to relevant electronic medical services for the disabled and the elderly and the population of remote regions and villages;

- continuous improvement of the health care system through more effective use of the latest health achievements;

- making more substantiated decisions on regulation, legal, financial, investment and research issues through the provision of access to different information;

- provision of patients' access to their electronic medical information at right time and place, and making reasonable decisions on care and treatment;

- provision of physician's access to all relevant information for more effective support and monitoring of the patient's health;

- provision of access to information on any disease, its prevention and treatment for doctors and patients

- provision of public access to medical information through the Internet or mobile telephony.

\section{International experience in e-medicine}

Currently, the health care system in entire world is being informatized. More than half of the world's states are operating in this field based on the methodology offered by WHO and ITU. Obviously, the implementation of any international innovation program in a certain country is based on the selection of the model taking into account the national characteristics. From this point of view, although there is no rich international experience in the field of e-medicine, each country has developed its unique model. These models depend on the development, organization and financing principles of the healthcare in the country. The state plays a crucial role in the establishment of the e-medical system. That is, the state is the main investor in this field and responsible for the funds of the taxpayers. 
Analysis of literary sources and the Internet publications shows that the introduction of ICT in the practical medicine is based on the implementation of the state programs and initiatives on ehealth development in different countries around the world. These programs and initiatives include the organization of the electronic document circulation, the maintenance of the current status of electronic record of the citizens, the development of telemedicine and monitoring system of the public health, the generation of the Internet resources, and the personalized accounting of the medical services [29]. For example, EU-funded E-Health Action Plan 2012-2020: Innovative Health of the 21 st Century program provides ICT solutions at national and transnational levels [30, 31].

The USA is implementing the "Integrated Development Program for Medical Sector" within the e-government and Canada is implementing the "Single E-medicine System Development Program" [32]. Within the framework of these programs, electronic health passport (record), personalized medical services, ICT infrastructure of e-medicine, e-document circulation, telemedicine, the establishment of inquiry data and classification registries are underway in the mentioned countries. At the same time, each of these countries has developed or is developing ehealth strategies. Thus, $70 \%$ of the 53 member states of the WHO European Region have adopted the national e-health policies or strategies [31].

Some CIS countries are also taking active measures for the introduction of ICT in medicine in. The "E-health" program of the Russian Federation out of these countries is the most developed. Thus, the Federal Agency for Technical Regulation and Metrology approved the National Standard of "Electronic Medical Record", which defines the general principles, terms and definitions, structure and application fields, and adopted the concept of establishing a single state information system in the field of medicine [33].

Kazakhstan, Uzbekistan, Belorussia, Ukraine, Moldova and Kyrgyzstan have established the centers for the informatization of medicine [34-39]. The Republic of Kazakhstan adopted the "Concept of E-medicine Development" for years 2013-2020. The Republic of Kyrgyzstan has also prepared a draft Concept of E-medicine Development. Moreover, a draft law on the approval of the State program "Health 2020: Ukraine dimension" has been prepared. The "Concept of the Single Integrated Medical Information System" has been adopted within the framework of the National Strategy "Electronic Moldova". The Republic of Belarus adopted the "National Development Program for ICT Services for 2015", in 2011. Within this program, the "E-health" subprogram is implemented. Its main tasks include the development of electronic document circulation, the development of monitoring system of telemedicine and population's health, and the creation of medical resources. Uzbekistan has also approved the National Concept for the Development of National Integrated Information System of healthcare in 2009, which describes the formation stages of e-health in the country in details. The Kyrgyz government approved a draft resolution on the approval of e-health program of the Republic of Kyrgyzstan for years 2016-2020.

\section{E-medicine in Azerbaijan}

Today, there are no separate conceptual and strategic documents on the informatization of medicine in Azerbaijan. The informatization processes of public health have been implemented based on the state programs "Electronic Azerbaijan (2003-2008)", "Electronic Azerbaijan (20102012)". Nowadays, they are being implemented in accordance with the conceptual documents as the National Strategy for the Development of the Information Society in the Republic of Azerbaijan for 2014-2020" and "Strategic Road Map on the Development of Telecommunication and Information Technologies in the Republic of Azerbaijan" [40, 41].

Within the framework of these programs and separate projects, EHR (for newborns) is provided, exemplary medical information system is developed, online order of medical examination record is available, and the registry of inquiry data and classification is created in Azerbaijan [42]. 
In May 2010, Health Informatization Center under the Ministry of Health of the Republic of Azerbaijan was established in connection with the development of e-health in Azerbaijan. The Center is performing the central functions on the public monitoring and the general coordination and management of the Health System Informatization.

There are a number of technical and organizational challenges to be resolved for the application of ICT in the medical sector of Azerbaijan. Currently, the healthcare is not systematically informatized. Separate clinics are available, where most business processes are informatized and local databases are created. These medical institutions digitally share the information about patients. However, the applied medical information systems (MIS) are the products of various IT companies, which do not correspond to one another, and obviously, they can not share information within a single e-health approach.

Since the healthcare providers choose medical software themselves, the problems of inconsistencies are constantly growing. The lack of uniform methodological approach to data collection, processing and storage, and the absence of infrastructure and systematic information system do not allow for accurately evaluating the health status of the Republic of Azerbaijan.

On the other hand, serious issues have arose in Azerbaijan for the formation of e-health in line with the National Strategy. To address these issues, the National Health Network, which ensures the secure the broadband network connection for all medical personnel, healthcare providers, should be established and developed. Furthermore, EHR system should be improved and provided to all age groups; MIS's application should be expanded and coordinated with the eHealth; medical resources for general use should be established; tele-medicine should be developed; and ICT knowledge of medical workforce should be promoted.

The priorities of the "Strategic Road Map on the Development of Telecommunication and Information Technologies in the Republic of Azerbaijan" approved by the Decree of the President of the Republic of Azerbaijan dated December 6, 2016, include the "Development of Integrated Continuous Electronic Health Infrastructure". The health information system, which will be developed as a core component of this infrastructure, will incorporate e-health information, electronic registration, digital descriptions and electronic prescription components.

\section{Scientific problems of e-medicine}

International practice shows that today the scientific bases of the informatization process are not sufficiently developed. The scientific problems of e-medicine directly depend on the goals and tendencies of its informatization and the digitization of the information, organizationalmanagement, treatment-diagnostics, personnel, resource, economics and others certain aspects of the medical institutions and aim at the solution of various issues. Some of these issues are related to the development of a general methodology for the informatization of the medical institutions, while the other part requires the development of specific issues related to the medical field [43]. These specific issues include the turnover of the electronic medical records and its standardization, the unification of medical information description, and the development of the architecture for the management system of software and database for medical applications, and mobile health care. In addition, the list of specific issues cover the development of electronic tools for sharing of the patient's information; continuous analysis, assessment and forecasting of the information collected in the health information database; the clinical and management decision support in e-health environment; provision of medical information safety; improvement of the quality of medical services; and extra costs reduction [44-46].

Below are some of the scientific problems arisen in different stages of the informatization process of medicine, which are challenging for professionals. 


\section{Integration problems in e-medicine}

The modern concept of ICT involves the collection of information obtained from different sources (medical records archives, results from laboratories, financial information, etc.) and the development of tools for data sharing.

Establishment and development of MISs and their integration in regional, institutional and national healthcare are quite multifunctional, complex and difficult issues [47]. Today, the theory, principles and methods of open systems are applied as the main integration tools [48]. In order to solve the problem of reconciliation of the information systems with different platforms, the agreed set of interfaces, protocols and data format standards should be used.

The MISs should provide the clinical and non-clinical data sharing by maintaining a semantic meaning. In this case, in addition to common standards, the specific health standards should be used for the solution of the problem of reconciliation. The formation of a single information space for clinical data should be based on the general classifications, terminology and communication standards.

\section{Standardization problems in e-medicine}

The standardization of the medical records in e-medicine, information sharing among different MISs is one of the most challenging problems in the world. The main difficulty is due to the availability of the excessive number of concepts and terminology used in modern medicine. According to the expert estimates, there are more than 2 million definitions and terms in this area. For example, the Oxford dictionary contains 615,000 words.

At the background of the increasing exchange of various information about the patient, the use of terminology, electronic records, digital descriptions standards and international classifications has become more definite. The key priorities for the coordination of different types and levels of MISs are related to the unification of national standards with the internationally accepted standards. From this point of view, the establishment of national standards supporting the medical document circulation on a single methodology, referring to international standards is one of the topical scientific and applied problems in the field of medical terminology. In most developed countries, the "Health Level Seven" (HL7) standard is used for MISs, the "Clinical Document Architecture" (CDA v.2.0) standard - for the unification of the clinical document architecture, the SNOMED (Systematized Nomenclature of Medicine - Clinical Terms) standard for medical terms nomenclature, and DICOM (Digital Imaging and Communications in Medicine) standard - for digital medical descriptions [49].

\section{Software and hardware tools}

a) Grid technologies in e-medicine is used to build an infrastructure that provides services for processing and integration of distributed bio-medical data. The EU e-medical system is widely using grid-technologies. The creators of e-medical system explain the advantages of applying this technology by three main factors: 1) increasing the availability and quality of medical services at the expense of rapid diagnosis; 2) reducing the cost of medical services at the expense of early detection of the disease; 3 ) reducing the medical errors and the selection of optimal treatment strategies through the use of computer programs that provide the access to the medical data [50].

b) Cloud technologies. At present, information systems and information technology applications in the software and hardware architecture of e-medicine are based on the ClientServer principle. Whereas the use of cloud technology is mainly limited to hosting electronic medical information for small businesses ( $S a a S$ model). However, cloud technologies have a wide range of medical opportunities. Therefore, existing architectures are predicted to gradually switch to cloud technologies. Cloud technologies may enable the creation of more effective and transparent data infrastructure through the reconciliation of data processing centers and MISs of healthcare institutions. Storing the primary medical data in clouds can provide secure data sharing 
among medical systems [51]. For example, various healthcare providers can store medical information in cloud and share information and monitor the clinical data at real-time, and acquires analytical information on different clinical situations [52].

\section{Information support for decision-making in clinical medicine}

Information support for the diagnostic and treatment decisions in clinical medicine is of the global tendencies of e-medicine. A number of factors can explain this: 1) medical disorders are manifested in different forms, and therefore, there is no unequivocal criteria for diagnosis and treatment; 2) each disease is based on a large number of input indicators; 3) these indicators are qualitative and quantitative, and their values are characterized by inaccuracies. An experienced physician combines the baseline data with personal practice to confirm own hypothesis, taking into account similar situations in a particular situation, and identifies atypical forms of the disease, and finally, predicts the dynamics of the process. It necessitates the imitation of logical judgments on the treatment and diagnostic decisions based on the knowledge and empirical experience of the physician. Obviously, knowledge-based intelligent systems (expert systems, decision-support systems) are used to collect, store, manipulate, and evaluate the knowledge of experienced physicians-experts, and to identify and make adequate decisions for each particular set of data. The basis of these systems is the knowledge base consisting of cause-and-effect relationships in the specific subject area of medicine available as various rules that imitate the doctor's views, their possible causes and development duration, clinical manifestations, diagnostic evaluation of the observed symptoms.

The use of expert systems and decision support systems in most different areas of clinical healthcare may reduce the number of physician errors. These systems can be used to solve the following issues: assistance in the diagnosis process, search for case studies (precedents), therapy control and planning, images recognition and interpretation, and the monitoring of clinical and pharmacological properties (toxicity) of drugs [53, 54].

The development of medical intellectual systems is related to the solution of many scientific problems. These problems include selection of effective methods of knowledge acquisition from experts, the development of the methods for expert data processing, including the methodology for building knowledge base of the expert systems, the methods for analysis, evaluation and decision-making, advanced user interface, and the tools for the knowledge base editing and installation, including the visualization of the decision making process, analysis of results, their interpretation and explanation.

\section{Security problems of personal data in e-medicine environment}

The problem of information security in the medical field is distinguished by its specificity. This peculiarity is related to more sensitive and private medical data. Thus, e-medicine grounds on EHR that contains the information about the health of the individual. EHR is a MIS compiled in a computer-compliant way, which provides the access to accurate and truthful information for making the necessary decisions and recommendations. Protection and safe transmission of PMI in the operation of these systems are directly influencing the development of e-medicine [55].

Security of PMI implies the protection of PMI from internal or external threats, transmitted or supported by electronic media and any other technical or communication devices, including their protection against leakage, theft, loss, unauthorized destruction, distortion, modification (counterfeiting), copy and blocking.

According to the international practice, solutions of security problems of MIS requires the provision of the followings: confidentiality (prevention of unauthorized access to PMI), integrity (provision of the reliability of the medical data information when sharing, protection against unauthorized modification of information), and availability (access to information and associated assets by the authorized users, including the resistance mode in case of excessive overloading of MIS) [56-58]. 
It is required to develop new scientific approaches and solutions to reliably ensure PMI's confidentiality [59].

\section{Researches in the field of tele-medicine}

One of the most important aspects of innovative healthcare is the development of telemedicine. These technologies provide remote consultation, examination, processing of primary information in highly specialized centers, and saving the time spent on examination, and increased accuracy of diagnostics. The research in the field of telemedicine is conducted in the following areas: remote monitoring of health indicators, the development of effective methods for the formalization and processing of medical data (descriptions and electrical signals (e.g. electrorecordiograms)); the development of the methods for the collection of distributed data and their rapid transmission to the integrated medical information system; the development of the methods and algorithms of data compression [60].

One of the dynamically developing trend of e-health is mobile telemedicine. Mobile telemedicine combines multiple satellite communication tools, mobile information technologies (phones, smartphones, and tablets) and various wireless communication technologies to provide wireless data transmission. Cellular telemedicine (mobile medicine) enables the patient to benefit from the remote treatment at home, uninterrupted tele-monitoring of the patient's health, and medical consultation [61]. The scientific problems of mobile medicine include integration of sensors to various portable accessories and mobile phones, the different approaches to mobile monitoring of the patient's health, accuracy and security of data acquired through wireless technologies.

\section{Large-scale data problems in e-medicine}

Modern medical institutions are generating large volumes of different types of data (Big Data). Big Data in the medical field is generated due to EHR, wearable sensors, stationary medical devices, results of various laboratory analyses; radiological images, statistical data collected for years in clinics, pharmacological relationships of the drugs, and decoded results of individuals' genome.

The development of mobile technologies and the Internet of Things has accelerated the growth of personal data [62,63].

The quality of medical care depends on how efficiently the doctors, administrators and governing bodies use this information. Big Data technologies may be used to support treatmentdiagnostic and organizational-management decisions $[64,65]$. Increased access to medical data offers deeper understanding of the relationships that are created on the basis of large amounts of data collected from various data sets using Big Data technologies and to convert the latter into new knowledge. The analysis of Big Data may reveal unexpected mutual relationships or patterns beyond human capabilities. One of the major trends in this field is to manage the health status of a patient and to support clinical decisions taking into account the health information of the previous years, including the results of current laboratory examinations, demographic characteristics (age, gender, and ethnic affiliation), drug response and the retrospective information about his/her interactions with the medicaments.

At present, the development of large-scale data analysis and summarization methods is one of the global challenges facing the scientists [66].

\section{Systems supporting the living ambient of the elderly}

At present, one of the global challenges is the aging of the world's population and the rapid increase in the number of people above 65. This process also increases the number of people suffering from the chronic diseases (arterial hypertension, heart failure, diabetes and memory disorders). This, in turn, contributes to the growth of health care costs. 
The role of ICT solutions in the improvement of the quality of medical services provided to the elderly and in the partial reduction of health expenditures is rising. Ambient Assisted Living $(A A L)$, which supports the living of the elderly, has great potential for the development of individual medicine and the involvement of citizens in the treatment of their illnesses by using ICT [67]. The $A A L$ system provides these people with medical transmitters, computers, wireless networks, software supplements, methods and services to support safe and healthy lives of the elderly and rehabilitating people [68]. The main objective of this system is to extend the lifetime through the use of ICT being more accessible to health care providers. Integration of the patients' EHR with the Internet-enabled smart-gadgets controlling the most important health indicators (sleep cycle, heart rate, pressure) allows physicians to monitor the latter in the real-time mode and provide telemedicine services [69]. Such systems can be successfully used for the rehabilitation and integration of people with disabilities into the community.

\section{Physician-patient-medical institution relationship in e-medicine}

The patient-oriented approach in the e-medical system has led to the transformations in the relationship between the physician and the patient. This problem, which is sufficiently actual, envisages the solution of a number of issues: the synthesis of the new system of relationships in the national health system; the impact of the new medical service market and the gradual transition of the physician-patient relations into the client-physician relations in the context of the formation of individual medicine on the quality of medical services and social and economic criteria; the development of the models for acceptable management of the patient-medical institution relations in e-medicine [70].

\section{Human resource management in the field of medicine}

The development of the scientific basis for managing human resources cover the following issues: monitoring of supply and demand for various qualified specialists in the field of medicine, their regional distribution and balancing, and the adaptation of medical education to labor market requirements [71-73].

Evidently, scientific support of e-medicine is not limited to the above mentioned trends and ICT problems. There are numerous multidisciplinary scientific problems in the informatization process of medicine. The future development of e-medicine depends on the resolution of these problems. Of course, most of them are related to the application of ICT in medicine. However, the introduction of ICT in almost all spheres of human activity, including medicine, creates other serious problems. These problems are the medical problems of ICT, such as information overloading, illnesses caused by ICT, lifestyle disorders formed by ICT, and ICT addiction.

\section{Scientific centers in e-medicine}

Coverage of the scientific problems of e-medicine and the urgency of modernization of health have increased the interest of the international scientific community in the studies in this area. Specialized scientific centers have been established in a number of EU countries. Other states have included academic and research institutions in the list of priorities [54, 74]. The database of European priorities and strategies in E-medicine has been set up. This database covers e-medicine files from 27 EU countries, including Turkey, Iceland, Liechtenstein, Norway and Switzerland [75]. The goals of the database are to gather, compare and identify best practices, and formulate regional and international cooperation. Some CIS countries are also conducting studies on ehealth. The presentation of the Department of Information Technology and Computing Systems of the Russian Academy of Sciences has prioritized the research activities in the field of medical informatics. The Medical Informatics Research Center at the Institute of Software Systems of the Russian Academy of Sciences [76], the Institute of Modern Information Technology of the Federal Research Center for Informatics and Management [77], and the United Institute of the Problems 
if Informatics of the National Academy of Sciences of Belarus [78] are also conducting fundamental and applied studies in bioinformatics and medical informatics.

\section{Conclusion}

The analysis of the world practice on the development of e-medicine allows us to conclude the followings:

1. Formation of the national e-medical system envisages the identification of the legal status of electronic documents, protection and secure transmission of confidential information about the patient, scientific and technological and human resource training, compliance with international standards.

2. Most countries have adopted the development concept and national programs that set priorities of the informatization for the establishment of e-medicine system.

3. Informatization process has many scientific problems, most of which are of global character and require large-scale scientific research.

4. Currently there are no specific conceptual and strategic documents on the informatization of health in Azerbaijan.

Based on the above-mentioned conclusions, it is important to develop a state program that envisages the implementation of political, administrative, regulatory-legal, personnel, scientificinnovative and technological-software measures on the formation and development of e-health in Azerbaijan.

\section{References}

1. Dzenowagis J. The health and care revolution. Ghent, EAI Publishing, 2011.

2. Building the foundation for e-health: achievements of Member States: report of the WHO Global Observatory on e-Health. Geneva, World Health Organization, 2006.

3. Cheong H.J., Shin N.Y., Joeng Y.B. Improving Korean Service Delivery System in Health Care: Focusing on Nationale-Health System, Proc.of the Int. conf. On e-Health, Telemedicine, and Social Medicine (eTELEMED'09), 1-7 Feb.2009, pp.263-268.

4. A set of materials on the national e-health strategy, WHO and ITU, 2012, $226 \mathrm{p}$.

5. Patient safety. Data and statistics. WHO/Europa. http://www.euro.who.int/en/healthtopics/Health-systems /patientsafety/data-and-statistics

6. Kohn L.T., Corrigan J.M. and Donaldson M.S. Building a Safer Health System / Washington: NationalAcademyPress, 1999.

7. Graban M. Statistics on Healthcare Quality and Patient Safety Problems - Errors \& Harm.2015.www.euro.who.int/en/health-topics/Health-systems/patientsafety/data-and-statistics).

8. A Nation Online: How Americans Are Expanding Their Use of the Internet. U.S. Commerce Department survey 2002, http://www.statusa.gov/pub.nsf/vwAbsInt/ nationonline?

9. Pavlenko E.V. Cyberspace of medicine: Internet as an enemy and ally of a physician and patient // Sociology of Medicine, 2013, No1, http://cyberleninka.ru/article /n/ kiberprostran

10. World Summit on the Information Society. Tunis-2005, http://www.itu.int/net/wsis index

11. WHA58.28 eHealth. Resolutions and decisions, http://www.who.int/healthacadem//WHA58-28-en

12. European Commission. eHealth-Key documents. http://eurlex.europa.eu/legal-content/ EN

13. International Telecommunication Union (ITU) Implementing e-Health in developing countries: Guidance and principles. Geneva: ITU, 2008, http://www.itu.int/ITU-D/cyb/app/ docs/e-Health_prefinal_15092008. PDF

14. Mitchell J. Increasing the cost-effectiveness of telemedicine by embracing e-health // Journal Telemed Telecare.2000; 6 Suppl 1: S16-9. 
15. Observatory for eHealth / World Health Organization, 2014, http://www.who.int/goe/ policies/ countries/en

16. Rosen E. The death of telemedicine? // Telemed Today. 2000, Vol. 8, no.1, pp.14-17

17. Elehealth, Telecare and Telemedicine...What's the Difference? http://evisit.com/ what-is- thedifference-between-telemedicine-telecareand-telehealth/

18. Telemedicine Definition. www.amdtelemedicine.com/telemedicineresources/html

19. Mea V.D. "What is e-Health (2): The death of telemedicine?" // Journal of Medical Internet Research, 2001, vol.3, no.2. www.jmir.org/2001/2/e22/

20. Eysenbach G."What is e-health?” // Journal of Medical Internet Research, 2001, vol.3, №2, e20. www.jmir.org/2001/2/e20/

21. Основной приоритет информатизации здравоохранения - ориентация на пациента, http://www.cnews.ru/news

22. Powell J., Buchan I. Electronic health records should support clinical research // Journal of Medical Internet Research, 2005, vol.7, no.1, http://www.jmir.org/2005/1/PDFp.e4.

23. Zingerman B. The electronic medical map and the principles of its organization, http:www.osp.ru/medit/blogs/bz/bz_109.html

24. National E-Health and Information Principal Committee.National EHealth Strategy, 30th September 2008. Adelaide, Deloitte Touche Tohmatsu, 2008.

25. Kohn L.T., Corrigan J.M. and Donaldson M.S. Building a Safer Health System, Washington: NationalAcademyPress, 1999.

26. Electronic Health Records: A Global Perspective. A Work Product of the MSS Enterprise Systems Steering Committee and the Global Enterprise Task Force. 2008.

27. Barello S., Triberti S., Graffigna G., Libreri C., Serino S., Hibbard J., Riva G. eHealth for Patient Engagement: A Systematic Review, 2015, http://www.ncbi.nlm.nih.gov/pubmed/ 26779108

28. E-Health for patient empowerment in Europa. 2007, https://joinup.ec.europa.eu/sites /pdf

29. Building foundations for eHealth: progress of member states: report of the Global Observatory for eHealth / World Health Organization, 2006, 339 p.

30. eHealth Action Plan 2012-2020: Innovative healthcare for the 21st century, https://ec.europa.eu/digital-single-market/en/news/ehealthaction-plan-2012-2020

31. From innovation to implementation - E-Health in the WHO European Region, http://www.euro.who.int/_data/assets/pdf_file/0012/302331/

32. General information on the foreign experience of standardization in the application of information technology in the organization of the provision of electronic services, http://asyan.org/potral

33. The concept of informatization of health in Russia, http://www.minzdrav.ru/_dr/0.pdf

34. The concept of e-health development of the Republic of Kazakhstan for 2013-2020, http://www.mzsr.gov.kz/taxonomy/term/557

35. Suiyumbaeva Ch. E-Health Project of Kyrgyzstan, http://icaren.org/files/KYRGYZSTAN_eHealth_Project

36. Implementation of eHealth: results and perspectives, 2015, http://www.minzdrav.uz/ictdevelopment/section-2/detail.php?ID=47617

37. The concept of the National Program "Health 2020: The Ukrainian Dimension", http://www.base.spinform.ru/show_doc.fwx?rgn=48284

38. The National Strategy for Building the Information Society - "Electronic Moldova".2005, http://www.rcc.org.ru

39. E-Healthcare in Belarus, http://www.pharmalegalblog.com/2015/08

40. National Strategy for the Development of the Information Society in the Republic of Azerbaijan for 2014-2020, http://www.e-gov.az/news 
41. Strategic Road Map on Development of Telecommunication and Information Technologies in the Republic of Azerbaijan, 2016, http://www.president.az

42. http://www.e-sehiyye.gov.az/az/s/9

43. Nazarenko G.I., Guliev Ya.I., Ermakov D.E. Medical information systems: theory and practice, Moscow: FIZMATLIT, 2005, 320 p.

44. Sutton M. Corporate document flow: Principles, technologies, implementation methodology, St. Petersburg: Azbuka, 2002, 448 p.

45. Relational and Object-Oriented Databases, http://www.issc.uj.ac.za/downloads/db.pdf

46. Patricia N. Mechael. The Case for mHealth in Developing countries // Innovations. Cambridge, MA: MIT Press, 2009, vol.4, no.1, pp.103-118.

47. Dabagov A.R. Informatization of health care and some problems of building integrated medical systems // Journal of Radioelectronics, No9, 2011, http://www.jre.cplire.ru/win/sep11/2/text.html

48. Chernyak L. Open systems and complexity problems // Journal of Open Systems, http://www.osp.ru/os/2004/08/185094/

49. E-health Standards and Interoperability. ITU-T Technology Watch Report, 2012, http://www.itu.int/dms_pub/itu-t/oth/23/01/T23010000170001PDFE.pdf

50. Eugster J.. Schmid M. Grid and Cloud Computing Methods in Biomedical Research // Journal Methods of Information in Medicine, 2013, no.1, pp.62-64.

51. Cloud computing. Bateman A., Wood M. // Journal "Bioinformatics", 2009, vol.15, №25:1475.

52. Pepus G. The world of super integration, http://www.kmworld.com/ArticleID=35771)

53. Sittig D.F., Wright A., Osheroff J.A, Middleton B., Teich J.M, Ash J.S., et al. Grand challenges in clinical decision support // Journal Biomed Inform, 2008, Vol. 41, no.2, pp.387-392.

54. Wilk S., Michalowski W. A Task-based Support Architecture for Developing Point-of-care Clinical Decision Support Systems for the Emergency Department, Institute of Computing Science, Poznan University of Technology, Poland // Journal Methods of Information in Medicine, 2013, no.1, pp.18-32.

55. Mammadova M.H. The problems of information security of electronic personal health data $17^{\text {th }}$ IEEE International Conference on IT in Medicine and Education, China, November 1315, 2015, pp.678-682.

56. Kobrinsky B.A. Confidentiality and protection of personal medical data in eHealth system. Federal Directory, http://www.federalbook.ru

57. Ameen M. A., Liu J. W. and Kwak K. Security and privacy issues in wireless sensor net- works for healthcare applications // Journal of Medical System, 2012, vol.36, no.1, pp.93-101.

58. Baker D.B. Privacy and Security in Public Health: Maintaining the Delicate Balance between Personal Privacy and Population Safety / The $22^{\text {nd }}$ Annual Computer Security Applications Conference, 2006, pp.3-22.

59. Wiktoria Wilkowska and Martina Ziefle. Privacy and data security in e-health: Requirements from the user's perspective / Health Informatics Journal, 18(3), pp.195-201.

60. Tove Sorensen.WHO Collaborating Centre for Telemedicine and e-health. Annual report 2009. The Norwegian Centre for Integrated Care and Telemedicine, $21 \mathrm{p}$.

61. Global Observatory on e-Health, the World Health Organization, 2013. apps.who.int/iri; Mobile Medical Application, http://www.fda.gov

62. Internet-of-Everything makes everything possible..., http://www.internet-of-everything.no/

63. mHealth: New horizons for health through mobile technologies.WHO. Global Observatory for eHealth series, Vol. 3, 112p, http://www.who.int/goe/publications/-goe_mhealth_web.pd f.

64. Mammadova M.H. Big Data in Electronic Medicine: Opportunities, Challenges and Prospects // Problems of Information Technology, 2016, No2, pp. 9-29. 
65. How Data Analytics can help in Decision Making in Healthcare. A Saviance Technologies Whitepaper, http://www.sharinghealthcaresolutions.covidien.com/how-do-you- use-big-datadrive

66. Trish-Williams. Big Health Data - the challenges and connections. Research Group of Computer and Security Science of Edith Cowan University, http://www.ecu.edu.au

67. Belbachir A., Drobics M., Marschitz W. Ambient assisted living for ageing well //An overview. Elektrotech. Inform. 2010, Vol.127, pp.200-205

68. Providing for Older Adults Using Smart Environment Technologies, http://www.todaysengineer.org/2007/may/smart_homes.asp.)

69. Memon M., Wagner S.R., Pedersen C.F., Beevi F.H., Hansen F.O. Ambient Assisted Living Healthcare Frameworks, Platforms, Standards, and Quality Attributes // Journal Sensors, Basel, Switzerland, 2014, Vol.14, no.3, pp. 4312-4341.

70. Togunov I.A. About the evolution of the relationship between the physician and patient in the health care system. Proceeding of the scientific-practical conference "Health Management", November 14-15, 2000, Moscow, pp.76-81

71. Systerova A.A. Conceptual framework for optimizing the management of medical personnel. thesis, Moscow, 2008, 48 p.

72. Mammadova M.H., Jabrayilova Z.G. Development of a multi-scenario approach to intelligent management of human resources in the field of medicine // Eastern-European Journal of Enterprise Technologies, 2017, №2/3(86), pp.4-14

73. Mammadova M.G., Mamedzade F.R. Conceptual Approaches to the Intelligent Management of the IT Labor Market // Problems of Information Technologies, 2013, No2 (8), pp.43-54

74. Mammadova M.H., Jabrayilova Z.G. Pattern Recognition in Supply and Demand Management for Medical Professionals / XIII International Scientific and Technical Conference "Recognition - 2017" May 16 - 19, 2017, Kursk, Russia, pp. 232-235.

75. eHealth and Informatics Research. Health Informatics Group at Swansea University. Wales, http://www.ecu.edu.auschools/computer-and-security-science

76. eHealth priorities and strategies in European countries. eHealth ERA report. March 2007, http://www.ehealth-era.org/indexold.htm

77. Medical Informatics Research Center, http://www.skif.pereslavl.ru/psi-info/interin/index.ru.html

78. Institute of Modern Information Technologies in Medicine, http://www.frccsc.ru/frc/isitm

79. United Institute for the Problems of Informatics of the National Academy of Sciences of Belarus, http://www.asio.basnet.by/about/priority_areas.php 